\title{
Domestic Violence among Ever Married Women of Reproductive Age Group in a Slum Area of Bhubaneswar
}

\author{
Authors \\ Dr Ipsa Mohapatra ${ }^{1}$, Dr Chitrangada Mistry ${ }^{2}$ \\ ${ }^{1}$ Assistant Professor, Dept of Community Medicine, Kalinga Institute of Medical Sciences, Bhubaneswar, \\ Email:dr_ipsa@yahoo.co.in, Contact No: 9861817092 \\ ${ }^{2}$ Post Graduate Student, Dept of Community Medicine, Kalinga Institute of Medical Sciences, Bhubaneswar, \\ Email: chitra.m990@gmail.com, Contact No: 9078937676 \\ Corresponding Author \\ Ipsa Mohapatra \\ Assistant Professor, Dept of Community Medicine, Kalinga Institute of Medical Sciences, Bhubaneswar
}

\begin{abstract}
Domestic violence is a deep-rooted evil in our society, which has an impact on the women's health and wellbeing. In a nationwide survey in India, it was observed that 37.2\% of women experienced violence after marriage. The study was undertaken to determine the prevalence of domestic violence and to identify factors associated with domestic violence, among the ever-married women in reproductive age group in an urban slum of Bhubaneswar city. It was a community based cross-sectional study, conducted in a slum area of Niladri Vihar, Bhubaneswar. The overall prevalence of domestic violence was 35\%, of which $34 \%$ suffered from physical, $17 \%$ from sexual and $35 \%$ emotional violence. Husbands' were mainly the perprators of crime, followed by in-laws. Presence of property, higher educational qualification and social support were protective factors against domestic violence, whereas alcohol addiction and illeteracy of husband were important contributory factors for it. The prevalence of domestic violence in this study was comparable with studies done in other parts of India. The study recommends more social support, awareness and income generation for women in the slum areas.
\end{abstract}

Keywords: Physical violence, Domestic violence, Social support, urban slum, ever married, women.

\section{Introduction}

Violence against women is a global public health problem that affects approximately one third of women globally. Violence against women, is neither a new phenomenon, nor is its consequences on women's physical, mental and reproductive health. What is new is the growing recognition that acts of violence against women are not isolated events but rather form a pattern of behaviour that violates the rights of women and girls, limits their participation in society, and damages their health and well-being. [1] There is growing recognition that violence against women has a large public health impact, in addition to being a gross violation of women's human rights. ${ }^{[2]}$

Most recently, the agreed conclusions of the 57th session of the Commission on the Status of Women, [3] emphasized the importance both of addressing 
structural and underlying causes and risk factors in order to prevent violence against women and girls, and of strengthening multisectoral services, programmes and responses for victims and survivors. The agreed conclusions also called for continued multidisciplinary research and analysis on the causes of, and cost and risk factors for, violence against women and girls, in order to form laws, policies, strategies, and support awareness raising efforts.

Domestic violence is a global issue, reaching across national boundaries as well as socio-economic, cultural, racial and class distributions. It is a widespread, deeply ingrained evil, which has serious impact on woman's health and well-being. Domestic violence can be described as the power, misused by one adult in a relationship, to control another. It is perpetrated by and on both men and women. However, most commonly the victims are women and the perpetrators are their husbands. ${ }^{[1]}$

National Family Health Survey (NFHS) - III carried out in 29 states of India in 2005-06 has found that, 34 percent of women aged 15-49 had experienced physical violence, and 9 percent had experienced sexual violence. In all, 35 percent of women age 1549 in India had experienced physical or sexual violence. By state, women's experience of physical or sexual violence ranges from a low of 6 percent in Himachal Pradesh to 40 percent or more in Rajasthan, Madhya Pradesh, and Tripura, and to a high of 56 percent in Bihar. ${ }^{[4]}$

Few studies ${ }^{[5,6]}$ have shown the prevalence of domestic violence to be higher in slum population than in general population. Studies done in slum population in Bangalore ${ }^{[5]}$ and Kolkotta ${ }^{[6]}$ have reported it as $50 \%$ and $66 \%$, respectively, whereas relevant data are scarce in Bhubaneswar, the capital city of Odisha, a state in Eastern India.

Thus, this study was conducted in the urban slums under the fied practice area of Urban Health \& Training Centre[UHTC], of Kalinga Institute of Medical Sciences [KIMS], Bhubaneswar, with the objectives, to find out the prevalence of domestic violence among the ever married women in reproductive age group (15-49) in the slum population under study, to assess the types of domestic violence among them and to identify the factors associated with it.

\section{Methods}

This descriptive cross-sectional, community based study was conducted in the 5 slums under the field practice area of Urban Health \& Training Centre [UHTC] of Kalinga Institute of Medical Sciences [KIMS], Bhubaneswar. The total families in these slums are 3255 with a total population of 12,152 (2011 census). 15-49 year females constituted 57.4\% of the female population. Sex ratio was 978 females per 1000 males in the study area. Study population constituted of all the ever-married women in the reproductive age group residing in that slum area, with the following inclusion and exclusion criteria:

\section{Inclusion Criteria}

1. Married women more than 18 years of age

2. Residents of the selected area for more than one year.

3. Those who were willing to participate in the study and gave an informed written consent.

\section{Exclusion Criteria:}

1. Married women who were not available during the period of visit

2. Those with chronic debilitating diseases.

3. Those who were mentally incapacitated.

4. Pregnant lady.

\section{Sample Size:}

Taking the prevalence of domestic violence as $35 \%$ (NFHS 3) [4], with 95\% confidence interval and absolute precision of $10 \%$, and $10 \%$ non-response rate, sample size was calculated to be 100 .

Study Instrument: A pre-designed, pre-tested, semi-structured questionnaire with details of sociodemographic profile, their perception on domestic violence and self-reported experiences ofany occurrence of domestic violence (physical, emotional and sexual) imparted on them was enquired. Social support and presence of property were assessed by asking the relevant questions to the respondent. Proforma was prepared in local language (Odia) with the help of technical experts. 
Study Technique: From the family folders of UHTC, list of all the ever-married women in the reproductive age group, satisfying inclusion criteria, residing in that slum was prepared. 100 women were randomly picked up from this. Interview was done in their respective households, in the absence of their guardian / husband, but in presence of the local Female Health Worker (FHW).

Study period: January 2016- April 2016. Working definitions of forms of exposure to violence used: ${ }^{[1]}$

Self-reported experienceof one or more acts, of physical and/or sexual and/or emotional violence by a current or former partner since the age of 18 years. Domestic violence was used as per definition of the United Nations as "any act of gender-based violence that results in, or is likely to result in physical, sexual or psychological harm or suffering to women, including threats of such acts, coercion or arbitrary deprivations of liberty, whether occurring in public or private life".

Physical violence is defined as: being slapped or having something thrown at you that could hurt you, being pushed or shoved, being hit with a fist or something else that could hurt, being kicked, dragged or beaten up, being choked or burnt on purpose, and/or being threatened with, or actually, having a gun, knife or other weapon used on you. ${ }^{[1]}$ Sexual violence is defined as: being physically forced to have sexual intercourse when you did not want to, having sexual intercourse because you were afraid of what your partner might do, and/or being forced to do something sexual that you found humiliating or degrading. ${ }^{[1]}$

Current violence: Self-reported experience of violence in the past year. ${ }^{[1]}$

Prior violence: Self-reported experience of violence before the past year. ${ }^{[1]}$

Data was entered into Microsoft excel 2007. Descriptive measures like frequency was used to summarize the socio-demographic data of the subjects. In order to compare the distribution of various socio-demographic factors between subjects with or without domestic violence, chi-square test was used. p-value of $<0.05$ was taken as the level of significance. Data was analyzed by Epi Info 3.4.3 version.

Ethical clearance was obtained from Institutional Ethics Committee, KIMS \& PBM Hospital, before the study. Magnitude of the problem of domestic violence and objectives of the study were explained to the study subjects before interview and a written informed consent was taken (in this study, none refused to give consent). Assurance about the anonymity and not disclosing the details of interview to husband / guardian was ensured.

\section{Results}

In the present study, data was collected from 100 ever married women in the reproductive age group (mean age 34.54 \pm 9.20 years). Mean age of their husbands were $36.52 \pm 8.6$ years. Among the study population, $86 \%$ were Hindus and $12 \%$ were Muslims; 98\% were living with their husband and $2 \%$ with their parents. $19 \%$ were illiterate, $15 \%$ completed primary education, $19 \%$ read up to middle school, $22 \%$ passed secondary level and $25 \%$ studied up to higher secondary.

So far as occupation was concerned, $64 \%$ of the study population were homemakers, $15 \%$ were unskilled labourers, $13 \%$ were semi-skilled labourers, $2 \%$ were semi professional, $6 \%$ were self employed or having own business. Among the husbands $3 \%$ were unemployed, $1 \%$ were professionals, $35 \%$ were unskilled labourers, $45 \%$ were semi-skilled labourers, $5 \%$ were doing service and $11 \%$ were self employed.

Regarding social support of the study population, $61 \%$ had support from the natal family, $1 \%$ from neighbours, $3 \%$ from both and 35\% had no support. Regarding property, $86 \%$ had none and $14 \%$ had some property in the form of land, money, ornament alone or in combination.

In the present study, prevalence of domestic violence was found to be $35 \%$. The perpetrators were mostly the husbands, followed by other members of the family like mother-in-law, fatherin-law. When probed from the women, about the person, who actually perpetrated different violent behaviour. It revealed that husband $(18 \%)$ was 
mostly responsible for violence among majority of women. Some women reported that in-laws (husbands' parents) were also responsible for few acts of violence, particularly emotional violence $(29 \%)$. Few cases of physical violence wherein inlaws and husbands' kin's (7\%) involved were reported.

Emotional violence was more common than physical violence. So far as types of violence were concerned, $34 \%$ had faced one or more forms of emotional violence in their lifetime, whereas $17 \%$ were subjected to one or more forms of sexual violence. Slapping was the most common form of physical violence [Table 1].

Table 1: Types of violence among the domestic violence victims

\begin{tabular}{|c|c|c|}
\hline Type of violence & Current & Lifetime \\
\hline \multicolumn{3}{|c|}{$\begin{array}{l}\text { Physical Violence* } \\
\text { (Any form of physical violence) }[\mathrm{n}=34]\end{array}$} \\
\hline Slapped her & 14 & 34 \\
\hline Twisted her arm or pulled her & 12 & 16 \\
\hline $\begin{array}{l}\text { Pushed her, shook her or throw } \\
\text { something at her }\end{array}$ & 10 & 13 \\
\hline $\begin{array}{l}\text { Punch her with his fist or hurt with } \\
\text { something }\end{array}$ & 15 & 21 \\
\hline Kicked her, dragged her or beat her up & 6 & 11 \\
\hline $\begin{array}{l}\text { Tried to choke her or burn her on } \\
\text { purpose }\end{array}$ & 4 & 4 \\
\hline $\begin{array}{l}\text { Threaten or attack her with knife or } \\
\text { weapon }\end{array}$ & 6 & 7 \\
\hline Other reasons not cited above & 7 & 21 \\
\hline \multicolumn{3}{|l|}{$\begin{array}{l}\text { Emotional Violence* } \\
\text { (Any form of emotional violence) }[\mathrm{n}=35]\end{array}$} \\
\hline $\begin{array}{l}\text { Said or did something to humiliate her } \\
\text { in front of others }\end{array}$ & 18 & 21 \\
\hline $\begin{array}{l}\text { Threaten to hurt or harm her or } \\
\text { someone close to her }\end{array}$ & 1 & 6 \\
\hline $\begin{array}{l}\text { Insult her or made her to feel bad } \\
\text { about herself }\end{array}$ & 9 & 9 \\
\hline Other reasons not cited above & 26 & 34 \\
\hline \multicolumn{3}{|l|}{$\begin{array}{l}\text { Sexual Violence* } \\
\text { (Any form of sexual violence) }[n=17]\end{array}$} \\
\hline $\begin{array}{l}\text { Physically forced her to have sexual } \\
\text { intercourse with him even when she } \\
\text { did not want to }\end{array}$ & 11 & 15 \\
\hline $\begin{array}{l}\text { Force her to perform any sexual acts } \\
\text { she did not want to }\end{array}$ & 4 & 4 \\
\hline Other reasons not cited above & 3 & 5 \\
\hline $\begin{array}{l}\text { Any form of physical or sexual } \\
\text { violence or emotional violence }\end{array}$ & 26 & 35 \\
\hline
\end{tabular}

* Multiple responses
Hitting, beating and slapping were the commonest forms of physical violence. Insulting, threatening were the most common forms of emotional violence. Among the major factors associated with domestic violence, some serious issues came out such as, alcohol addiction of the husband, dowry related problems and not having a male child, as well as some inconspicuous reasons like not cooking properly or talking with neighbours, etc.[Figure 1].

Figure 1: Distribution of study subjects according to the main reasons of domestic violence

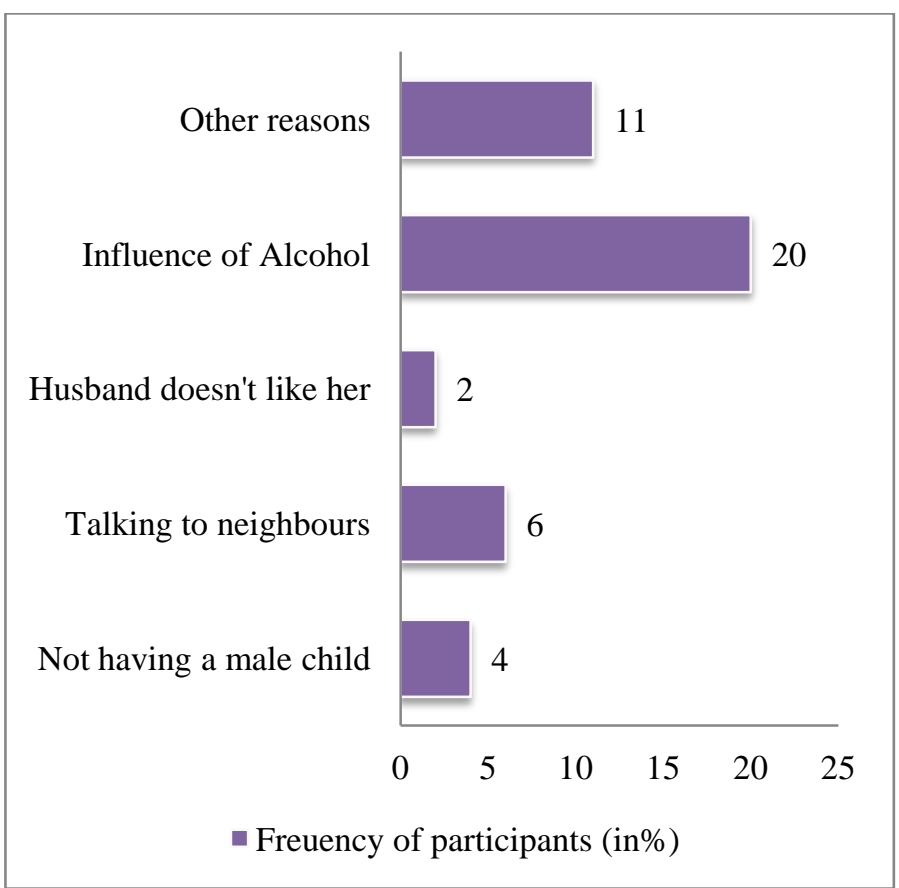

Spousal age difference, family structure did not have any association with prevalence of domestic violence. Domestic violence was observed significantly more when husbands had alcohol addiction, and literacy status and significantly less when women had some social support or property [Table 2]. 


\section{JMSCR VoI||05||Issue||03||Page 19593-19598||March}

Table 2: Distribution of the factors associated with domestic violence among the study subjects $(\mathrm{N}=35)$

\begin{tabular}{|c|c|c|c|c|}
\hline $\begin{array}{ll}\text { Factors of } \\
\text { domestic } \\
\text { violence }\end{array}$ & $\begin{array}{l}\text { Domestic } \\
\text { violence } \\
\text { present } \\
\end{array}$ & $\begin{array}{l}\text { Domestic } \\
\text { violence } \\
\text { absent } \\
\end{array}$ & Total & p-value \\
\hline \multicolumn{5}{|c|}{ Age Difference of the couple } \\
\hline $\begin{array}{l}\text { Less than } \\
\text { lequal to } 5 \\
\text { yrs }\end{array}$ & 24 & 41 & 65 & \multirow[t]{2}{*}{0.7401} \\
\hline $\begin{array}{l}\text { Greater than } \\
5 \text { yrs }\end{array}$ & 11 & 24 & 35 & \\
\hline \multicolumn{5}{|c|}{ Alcohol addiction of the husband } \\
\hline Present & 30 & 5 & 35 & \multirow[t]{2}{*}{$<0.0001$} \\
\hline Absent & 5 & 60 & 65 & \\
\hline \multicolumn{5}{|c|}{ Social support of the wife } \\
\hline Present & 15 & 49 & 64 & \multirow[t]{2}{*}{0.0026} \\
\hline Absent & 20 & 16 & 36 & \\
\hline \multicolumn{5}{|l|}{ Family type } \\
\hline Nuclear & 21 & 47 & 68 & \multirow[t]{2}{*}{0.3009} \\
\hline Joint & 14 & 18 & 32 & \\
\hline \multicolumn{5}{|c|}{ Education status of wife } \\
\hline Literate & 24 & 57 & 81 & \multirow[t]{2}{*}{0.0397} \\
\hline Illiterate & 11 & 8 & 19 & \\
\hline \multicolumn{5}{|c|}{ Education status of husband } \\
\hline Literate & 19 & 62 & 81 & \multirow{2}{*}{$<0.0001$} \\
\hline Illiterate & 16 & 3 & 19 & \\
\hline \multicolumn{5}{|c|}{ Occupational status of wife } \\
\hline Unemployed & 19 & 45 & 64 & \multirow[t]{2}{*}{0.2059} \\
\hline Employed & 16 & 20 & 36 & \\
\hline \multicolumn{5}{|c|}{ Occupational status of husband } \\
\hline Unemployed & 3 & 0 & 3 & \multirow[t]{2}{*}{0.07} \\
\hline Employed & 32 & 65 & 97 & \\
\hline \multicolumn{5}{|c|}{ Per capita income of the family } \\
\hline BPL & 4 & 2 & 6 & \multirow[t]{2}{*}{0.216} \\
\hline APL & 31 & 63 & 94 & \\
\hline \multicolumn{5}{|c|}{ Property of wife } \\
\hline Present & 0 & 14 & 14 & \multirow[t]{2}{*}{0.008} \\
\hline Absent & 35 & 51 & 86 & \\
\hline
\end{tabular}

Presence of social support of wife, property of wife, educational status of both husband and wife had a positive impact and was significantly less associated with domestic violence; while alcohol addiction of husband and illiteracy of husband were found to have significant influence on presence of domestic violence. Though, no significant difference was found so faras occupation of wife was concerned.

\section{Discussion}

Violence against women is a major public health problem, which affects physical, mental and reproductive health.

The overall prevalence of domestic violence in our study population was found to be $35 \%$. With regard to prevalence of domestic violence, findings were similar to that found in the NFHS $3^{[4]}$, where $37.2 \%$ of women had experienced one or more form of domestic violence. This is almost similar to the findings of many studies with $54 \%, 36.9 \% \%$ women reporting domestic violence in India. ${ }^{[6,7]}$

On comparing the prevalence of different forms of domestic violence in our findings to many population based studies, the prevalence of physical violence was found to be the same, i.e. around 14 $34 \%$ in other studies, ${ }^{[7,8]}$ while that of emotional violence was found tobe higher than other studies. Accordinf to NFHS-3, the prevalence of emotional violence was around $15.8 \% .{ }^{[8]}$

Regarding alcohol influence among participants who experienced domestic violence, a similar inference was drawn from other studies which found that physical (67.6\%) and emotional (38.6\%) abuse was significantly higher. [8] Husband's consumption of alcohol was found to be a significant factor associated with violence. Evidence from other studies supported husbands alcohol consumption as a significant factor of domestic violence[6] and might be because of reduced selfcontrol of individuals due to excessive alcohol consumption.

Working women were found more likely to experience violence than women who were not working in the present study.

Our study had certain limitations. Firstly, as the data was collected on self-reported experience of domestic violence by respondents, there may be under or over reporting because of the sensitive nature of the issues related to domestic violence due to social desirability bias. Secondly, as we collected data on "lifetime/past experience of domestic violence", there are chances of recall bias. Lastly, being a cross-sectional study it was not possible to establish causal relationship between the sociodemographic factors studied and domestic violence. Further, the findings may not represent the whole slum communities of all women of reproductive age group. 


\section{Conclusion}

The study showed the existence of domestic violence in the sampled urban slum community. Violence against women is not only a form of discrimination and violation of human rights, it also causes untold misery, cutting short lives and leaving countless women living in pain and fear in every country in the world. Factors like early illeteracy of husband and husband's drinking alcohol habit were significantly associated with the domestic violence. As domestic violence is found to be deep rooted in the socio-cultural practices and both the perpetrators as well as victim take it for granted, there is need of major transformation in the socio-cultural milieu and stringent law against perpetrators. As no public health response is complete without prevention. Violence against women can and should be prevented. Promising programmes exist and many hinge on promoting gender equality so that the full potential of the world's women and girls can be realized.The study recommends more social support, awareness and income generation for women in the slum areas.

\section{Acknowledgement}

Authors acknowledge the staff of the UHTC, the female health workers who facilitated for data collection; and all the study participants for their cooperation and time

\section{References}

1. World Health Organisation. Global and Regional Estimates of Violence Against Women. WHO. [Last cited on 2016 May 23].

Available from:http://www.who.int/reproductivehealth /publications/violence/9789241564625/en/

2. Report of the Fourth World Conference on Women. New York, United Nations, 1995 (A/ CONF.177/20/Rev.1) (http://www.un.org/womenwatch/confer/beij ing/reports/, accessed1 April 2013)

3. The elimination and prevention of all forms of violence against women and girls: agreed conclusions. In: Commission on the Status
ofWomen, Fifty-seventh session, 4-15 March 2013. New York, United Nations, 2013 (http:// www.un.org/womenwatch/daw/csw/57sess. htm, accessed 1 April 2013).

4. International Institute for Population Sciences (IIPS), Macro International. National Family Health Survey (NFHS-3), 2005-2006: India. I. Mumbai: International Institute for Population Sciences; 2007

5. Rocca CH, Rathod S, Fallet, Rohini P, Pande RP, Krishnan S. Challenging assumptions about women empowerment: Social and economic resources and domestic violence among young married women in urban South India. Int $\mathrm{J}$ Epidemiol 2008;38:577-85.

6. Sinha A, Mallik S, Sanyal D, Dasgupta S, Pal D, Mukherjee A. Domestic violence among ever married women of reproductive age group in a slum area of Kolkata. Indian J Public Health 2012;56:31-6.

7. Prateek S Shrivastava, Saurabh R Shrivastava. A Study of Spousal Domestic Violence in an Urban Slum of Mumbai Int $\mathbf{J}$ Prev Med. 2013 Jan; 4(1): 27-32.

8. http://rchiips.org/nfhs/NFHS-/VOL1/Chapter $2015 \quad$ Domestic Violence(468K).pdf

9. http://rchiips.org/nfhs/nfhs4.shtml http://rchiips.org/NFHS/pdf/NFHS4/India.p df 